Daniel Mansuy, Nos fuimos quedando en silencio. La agonía del Chile de la transición (Santiago: Instituto de Estudios de la Sociedad, 2016).

RESEÑA

\title{
UN COSTOSO SILENCIO
}

\author{
Ignacio Briones $\mathrm{R}$.
}

Universidad Adolfo Ibáñez

D aniel Mansuy es uno de los más talentosos intelectuales jóvenes de centroderecha. Y eso queda de manifiesto en su libro Nos fuimos quedando en silencio. ${ }^{1}$ En él, el académico y doctor en ciencias políticas nos ofrece una aguda e ilustrada reflexión sobre los factores evolutivos que permiten entender el estado actual de la política en Chile y de su crisis de legitimidad. Las principales fuerzas políticas, nos plantea, se quedaron mudas a la hora de internalizar gradualmente las nuevas demandas y desafecciones de la sociedad chilena. Incapaces de anticiparlas, sencillamente se encontraron de golpe con ellas. Algunos reaccionaron con facilismo; otros, con parálisis.

¿Cómo explicar el ciclo político que se inicia luego de las movilizaciones de 2011? ¿Cómo entender la repentina renuncia, casi con vergüenza, por parte de la vieja Concertación de aquello que la convirtió en la coalición política más exitosa de la historia de Chile, tanto desde una perspectiva política como económica? Y respecto a la derecha, ¿cómo dar cuenta de la parálisis a la cual el nuevo escenario la ha dejado expuesta, sin que, hasta hoy, haya sido capaz de hacer un diagnóstico fino de la situación, ni menos plantear una hoja de ruta política de largo plazo? Estas son algunas de las preguntas que Mansuy nos invita a responder.

Ignacio Briones. PhD en economía por la Sciences-Po, París. Decano Escuela de Gobierno, Universidad Adolfo Ibáñez. Email: ignacio.briones@uai.cl.

${ }^{1}$ Santiago: Instituto de Estudios de la Sociedad, 2016. En adelante, este libro se citará tan sólo mencionando el número de página.

Estudios Públicos, 144 (primavera 2016), 341-364 ISSN: 0716-1115 (impresa), 0718-3089 (en línea) 
La tesis principal del libro puede resumirse en que luego de la recuperación de la democracia las dos principales coaliciones políticas vivieron en un cómodo silencio respecto de los fundamentos del modelo económico y social de Chile establecido en dictadura. Este silencio, a su vez, se fue retroalimentando con los innegables y notables éxitos económicos y sociales del país. Y así como nos fuimos quedando en silencio, otras voces se fueron soterradamente acumulando fuera de los intermediarios políticos tradicionales. El resultado lo estamos viviendo. Y el juicio de Mansuy es claro: el problema fue (y es) un déficit de política.

El libro debe leerse en clave de ensayo, un "ensayo cartográfico", como lo define su autor, que no pretende delinear con precisión todos los contornos, sino que simplemente ambiciona a comprender sus particiones centrales. Se trata de dar cuenta de lo fundamental de la nueva disposición de las piezas políticas en el tablero y, al mismo tiempo, iluminar opciones para salir de la crisis. Y esta cartografía está dibujada con una pluma encomiable, lúcida, ilustrada y reflexiva, que deriva en un libro que se lee con tanto interés como placer.

El libro se estructura en siete capítulos. En el primero, a modo de introducción, Mansuy presenta un diagnóstico general de la situación actual. Enseguida retrata el origen del llamado "modelo" chileno, sus fundamentos institucionales -indispensables para entender la política luego del retorno a la democracia- y la influencia seminal que en éste tuvo Jaime Guzmán. Los siguientes dos capítulos se centran en la transición, poniendo el acento en los defectos políticos que explicarían el momento actual. El quinto capítulo hace una pertinente y lograda crítica del "régimen de lo público" desarrollado por el académico Fernando Atria, autor que, según Mansuy, ofrece la crítica más sofisticada e influyente de la transición y del "modelo". El sexto capítulo revisa los argumentos tradicionales de la derecha para defender el "modelo", denunciando la preocupante ausencia de un ideario político sustantivo de futuro. En el último capítulo, Mansuy esboza criterios en torno a los cuales sería urgente generar consensos políticos para enfrentar la nueva etapa, mirar hacia adelante y salir del embrollo.

En lo que sigue, presentaré los puntos centrales del libro, intercalando comentarios y reflexiones personales en algunos aspectos que me parecen relevantes. 


\section{EL MOMENTO JAIME GUZMÁN}

Para entender el momento político actual, Mansuy nos invita a remontarnos a los fundamentos institucionales erigidos en dictadura y cuyo personaje gravitante sería Jaime Guzmán. Aunque sin explicitarlo, lo que Mansuy intenta dibujar es la estructura de incentivos contenida en las reglas del juego institucionales heredadas de la dictadura, y cómo ellas habrían moldeado el comportamiento de los actores políticos luego del retorno a la democracia.

Guzmán es presentado como un político excepcional en el sentido que le da Maquiavelo (autor al que Mansuy — un entendido en la obra del florentino - apela a lo largo de todo el libro): el del político que busca dominar la fortuna a través de las armas propias, y cuyos medios se adaptan siempre, por conveniencia, a las circunstancias en pos de un solo norte: hacerse del poder y mantenerse en él. ${ }^{2}$

Es así como Mansuy nos muestra a un Guzmán que se plantea de entrada la pregunta de si el gobierno militar debía ser "un paréntesis histórico en la vida nacional” o, por el contrario, “debía abrir una nueva etapa" con "un régimen que prolongue por largo tiempo la filosofía, el espíritu y el estilo de las Fuerzas Armadas" (24). Ante el quiebre institucional, lo que tiene a la vista el gremialista es la necesidad de dotar al país de un programa refundacional en dos dimensiones indisociables: la política y la económica. Se trata, por un lado, de reconstruir aquello que fracasó y, por otro lado, nos dice Mansuy, de minimizar el riesgo de que el socialismo, que estaría en la génesis del descalabro institucional, pudiera volver a desplegarse con fuerza. Así, Guzmán adopta un enfoque práctico, que prevé un retorno a la democracia pero bajo una forma protegida. Esto explicaría la existencia de los senadores designados, la preponderancia del Consejo de Seguridad Nacional (Cosena) o la existencia de supermayorías para reformas de envergadura. Lo que buscaba Guzmán, plantea convincentemente Mansuy, era neutralizar la política.

En lo económico Guzmán es presentado también como el responsable último del liberalismo económico del gobierno militar; por supuesto, no en su dimensión técnica, que viene del Ladrillo y de los Chi-

${ }^{2}$ No deja de ser interesante notar la coincidencia de roles con Maquiavelo: si este último fue consejero del Príncipe (Lorenzo de Medici), Guzmán lo fue de Pinochet. 
cago Boys, sino que en su articulación política. Es sabido que Guzmán no era doctrinariamente cercano al liberalismo económico. Entonces, ¿cómo situarlo como el promotor de éste de cara a Pinochet? Mansuy apela nuevamente a su genio maquiavélico. Guzmán actúa por simple conveniencia y oportunismo de cara al proyecto político que lo anima: mantenerse en el poder. Esto admite dos dimensiones. Por un lado, apostar a que la liberalización de los mercados y el éxito económico resultante serían funcionales al régimen para mantener adhesión popular. Y por otro, y ése es el eslabón clave, que quienes pudieran suceder a Pinochet en democracia mantuvieran los pilares esenciales del así llamado "modelo". Mansuy lo expresa con claridad: "La intención política de Guzmán, que explica su adhesión al programa liberal, parece haber sido la siguiente: si los individuos se acostumbran a ejercer grados crecientes de responsabilidad personal, la libertad se irá consolidando como principio de organización social, lo que constituye la garantía más segura contra el socialismo" (42). Y la intuición de Guzmán parece haberse mostrado cierta. Y es que, como lo reconocen detractores importantes del "modelo neoliberal", la actual aceptación y validación social de sus principios sería una de las dificultades mayores para efectuar un cambio de paradigma abrupto. ${ }^{3}$

Guzmán es a fin de cuentas — nos dice Mansuy - un hombre de acción y no un intelectual, un político de tomo y lomo en el sentido maquiavélico. Este mismo pragmatismo es el que lo mueve a instalar una versión empobrecida del concepto de subsidiariedad, deliberadamente confundida con el liberalismo económico en su expresión más rudimentaria. Según Mansuy, "la subsidiariedad leída por Guzmán pasa a significar crecientemente la prioridad de los particulares respecto del Estado en la vida económica, dejando de lado otros aspectos" (38). Esta confusión no es neutra en sus implicancias políticas. Es precisamente la visión distorsionada del concepto y del subsecuente Estado subsidiario la que es objeto de defensa desde la derecha y de ataques desde la izquierda, pese a que, como bien apunta Mansuy, la preocupación última de la subsidiariedad bien entendida es tener una sociedad civil vigorosa,

${ }^{3}$ Giorgo Boccardo y Carlos Ruiz, Los chilenos bajo el neoliberalismo. Clases y conflictos sociales (Santiago: Fundación NODO XXI y Ediciones El Desconcierto, 2014). 
y para ello la libertad económica es condición necesaria pero no suficiente. $^{4}$

¿En qué medida las reglas económico-institucionales fraguadas en dictadura habrían de determinar el comportamiento de los actores políticos en la transición? Es lo que Mansuy aborda en los siguientes dos capítulos.

\section{ESE CÓMODO SILENCIO}

¿Cómo se gesta y explica la transición chilena? Nuestro autor plantea que ésta queda predefinida en la estrategia de la oposición a la dictadura en los ochenta, al ejercer esa oposición desde la cancha y bajo las reglas del régimen militar.

Y fue exitosa. Mal que mal, ganó el plebiscito y logró elegir holgadamente a Patricio Aylwin, un resultado fruto del realismo político, con decisiones adecuadas a las circunstancias, que no necesitó someterse a los designios de la fortuna. En ese proceso emergen dos figuras medulares. La de Aylwin y, por supuesto, la de Boeninger, quien es el gran articulador político en la fase inicial del retorno a la democracia. Mansuy lo sintetiza bien: "Boeninger y Aylwin entienden mejor que nadie que la política es el arte de lo posible, y que más vale democracia limitada que continuación de la dictadura durante otros ocho largos años" (61).

Con todo, plantea Mansuy, la estrategia con que se enfrentó a la dictadura no sería neutra a la hora de gobernar. La movida inicial implicó continuar jugando con las reglas del régimen luego de iniciada la democracia. Según nuestro autor, se trató de un error de cálculo que habría generado un desajuste político estructural originario que marcaría toda la vida de la Concertación. Este desajuste se expresa por una "marcada distancia entre el discurso y la acción" (68); entre lo que ideológicamente se creía y lo que se ponía en práctica en el plano político y económico. Se habría fraguado así una cómoda convergencia con la oposición respecto a los pilares institucionales, políticos y económicos, heredados del régimen militar. Un hecho que la Concertación, al decir de Boeninger, "no estaba en condiciones de reconocer" (68), nos recuerda Mansuy. Es sobre este punto (y volveremos luego sobre

${ }^{4}$ Para un análisis detallado del concepto, ver Pablo Ortúzar (editor), Subsidiariedad. Más allá del Estado y del mercado (Santiago: Instituto de Estudios de la Sociedad, 2015). 
él) que nuestro autor se muestra extremadamente crítico. Según él, "la Concertación no tuvo el coraje suficiente para explicar públicamente sus decisiones" (69). En cambio, se habría contentado con invocar la excusa perfecta cada vez que fuera necesario: que las instituciones políticas (y la derecha) bloqueaban aquello que en realidad se quería hacer y que era afín al ideario de izquierda que habitaba en sus filas.

Detrás de esta suerte de "paz pactada" el sistema electoral binominal juega un rol crucial, tal cual lo señala Mansuy. Producto del binominal, la existencia de dos grandes bloques políticos obliga a negociaciones políticas continuas para abordar reformas. Es lo que está detrás de la lógica de los consensos y de construir sobre lo ya obrado o, si se prefiere, que las reformas o cambios institucionales fueran graduales en lugar de refundacionales. Si estas características pueden ser vistas como ventajosas en términos de la coordinación política, la debilidad principal del binominal fue la falta de competencia. Y quien dice falta de competencia dice falta de innovación o de interés en captar y procesar nuevas sensibilidades y demandas ciudadanas. El binominal, así visto, simboliza lo que Mansuy denomina "un tipo de neutralización política" expresada en "un acuerdo tácito de no discutir cosas muy profundas" (87).

Sin embargo, el cómodo silencio no podía durar para siempre. Al final del día, la "neutralización de la política" a la que apela nuestro autor tendría consecuencias. Por un lado, la tensión interna en la coalición gobernante se fue intensificando (el viejo debate entre flagelantes y autocomplacientes), esperando el momento para salirse del cauce de la contención histórica. El primer hito se produce luego de la derrota electoral ante Piñera en 2010. El momento decisivo llega con las movilizaciones del 2011. El resto es historia conocida. Por supuesto, la oposición fue presa del mismo silencio. Mal que mal, se sentía cómoda con la evolución política y la lógica de los acuerdos que, manteniendo lo esencial del modelo económico y social, había producido una transición ejemplar y el periodo de mayor progreso económico en la historia de un Chile que, por vez primera, entraba de lleno en la modernidad.

\section{¿SOLO EL SILENCIO?}

Mansuy sugiere que el silencio de la transición fue, a la larga, una suerte de error político cuyas consecuencias se están pagando hoy. Esta tesis, me parece, debe ser matizada por al menos dos razones: 1) porque 
desde lo político hay razones para afirmar que fue un acierto más que un error; y 2) porque ni la crisis de legitimidad de las instituciones políticas, ni los cuestionamientos al capitalismo, que está en la esencia del modelo chileno, obedecen necesariamente a una incapacidad idiosincrática de la política local para procesar las nuevas demandas.

Respecto del primer punto, no cabe duda de que la Concertación fue extremadamente exitosa en la dimensión clave de la política que plantea Maquiavelo: hacerse del poder y dominar la fortuna para permanecer en él por largos veinte años, en lo que fuera el ciclo político y económico más exitoso en la historia de Chile. Sería un error evaluar esta performance con espejo retrovisor o apelando a su incapacidad de prolongarse en el poder por más tiempo. En esos términos, el tema de si la mantención del modelo por parte de la Concertación fue o no "a regañadientes" — como señala Mansuy — es relativamente irrelevante. Es más, hay buenas razones para pensar que lo obrado no fue ni a contrapelo ni estaba completamente bloqueado por la estructura institucional. Por un lado, las reformas efectuadas por la Concertación distan de haber sido cosméticas. La maciza reforma tributaria del gobierno de Aylwin, con un fuerte énfasis de concentrar los recursos en áreas sociales, proporciona un claro antecedente de entrada. Por otro, estar a contrapelo significa no profundizar en lo que supuestamente disgusta. Si éste fue el caso, ¿cómo entender la extensión y profundización de aspectos clave del modelo como, por ejemplo, la privatización de sanitarias, la licitación de carreteras, la firma de acuerdos de libre comercio o el celo por la responsabilidad fiscal? De hecho, el propio Mansuy muestra que incluso cuando la Concertación tuvo mayoría en el Congreso prefirió no inclinar la balanza a su favor. Aunque nuestro autor atribuya este hecho a una especie de atontamiento producto de la falta de costumbre de ser mayoría, la explicación más directa podría ser otra: un convencimiento profundo y legítimo de no querer cambiar. Los innegables éxitos económicos y sociales del período pueden haber retroalimentado este convencimiento por una razón que no se puede descartar sin más: la población valoraba dicho progreso. Y las urnas así lo reflejaron, un punto anticipado por Guzmán y que ningún político que aspire a permanecer en el poder podía obviar.

La segunda crítica a la tesis de Mansuy es que supone que los problemas de legitimidad y los cuestionamientos al modelo derivan necesariamente de la neutralización política propia del período de los 
consensos. No cabe duda de que en una situación de confort político hay menos incentivos para intermediar nuevas fuerzas o presiones sociales. En eso el autor indudablemente tiene un punto. Con todo, la primera pregunta que surge es si los cuestionamientos actuales no serían, en realidad, lo propio de las tensiones de la modernidad, a la que Chile accedió bajo la Concertación, y de las crecientes expectativas (cumplidas y decepcionadas) que de allí derivan. Pocas dudas caben respecto a que la sociedad chilena se encuentra hoy en un estadio de progreso y libertades que nunca en su historia conoció, un estadio que, con independencia del sistema político que se tenga, naturalmente reclama nuevas exigencias, sociales, políticas y económicas.

Una segunda cuestión relevante es si las tensiones en materia de confianza y legitimidad institucional son o no problema idiosincrático de Chile. Lo cierto es que estas tensiones parecen ser globales, tal como lo muestran distintos indicadores de la OCDE. ${ }^{5}$ En el mundo entero hay, en distintos grados, cuestionamientos a algunas de las manifestaciones del capitalismo. Particularmente relevante es la oposición al llamado capitalismo crónico o de amigotes y a la incestuosa relación entre política y dinero, puntos que han dado pie a una vasta literatura reciente. ${ }^{6}$

\section{DEL SILENCIO AL MOMENTO IDEOLÓGICO}

Para Mansuy las movilizaciones de 2011 son un hito crítico en tanto habrían develado las ambigüedades de la transición, marcando el fin de la vieja Concertación, la emergencia de la Nueva Mayoría y la sorpresa e inmovilismo de la derecha. Fue el momento en que se pusieron en cuestión aspectos esenciales del llamado modelo y de los consensos que lo soportaban. Por primera vez en muchos años Chile se enfrentaba a un momento verdaderamente ideológico, con un marcado giro hacia la izquierda.

Si la élite política no fue capaz de procesar de forma endógena y oportuna las tensiones que el sistema venía acumulando, la pregunta

\footnotetext{
${ }^{5}$ Ver, por ejemplo, OECD, Society at a Glance 2014, chap. 7: "Social Cohesion Indicators" (Paris: OECD, 2014).

${ }^{6}$ Ver, por ejemplo, Raghuram Rajan y Luigi Zingales, Saving Capitalism from the Capitalists (Princeton: Princeton University Press, 2004); Luigi Zingales, A Capitalism for the People: Recapturing the Lost Genius of American Prosperity (New York: Basic Books, 2012).
} 
es si dicho golpe fue asestado con igual fuerza en la derecha que en la izquierda. La respuesta es negativa, sugiere Mansuy. La Concertación transformada en la Nueva Mayoría estaba lejos de carecer, de facto, de un proyecto político al cual echar mano para responder a las nuevas exigencias sociales. Porque si bien esta reflexión política no nace de los partidos, sí venía siendo desarrollada por intelectuales que anticiparon acertadamente lo que la Concertación no. Entre éstos sobresale el abogado Fernando Atria y su tesis del régimen de lo público, muy influyente en el movimiento estudiantil y en la orientación programática de la Nueva Mayoría. Al exterior de las filas de lo que fuera la Concertación, es destacable además la figura de Carlos Ruiz Encina, quien también tendrá un ascendente en el movimiento estudiantil y en lo que será la Izquierda Autónoma. La derecha, en cambio, no gozó del mismo destino. Mansuy plantea que la era de los acuerdos fue especialmente dañina en ese sector a la hora de pensar en un proyecto político de largo plazo y con vocación de poder. La razón es simple: se habría encontrado particularmente cómoda con la mantención casi inalterada del modelo económico y social existente.

Éstas son las cuestiones que Mansuy desarrolla en detalle en los capítulos 5 y 6 .

\section{LA DERECHA ALETARGADA}

Según Mansuy, uno de los problemas fundamentales de la derecha fue que descansó en una visión economicista, anclada en la gestión y con una fe ciega en las soluciones de mercado en todo orden de cosas, pero completamente disociada de la política. Confiada en un sistema económico que parecía operar con piloto automático, no requería de la política para validar los objetivos, bondades y éxitos de éste. De allí que, según Mansuy, renunciara a tener un verdadero proyecto político de largo plazo.

Lo anterior, plantea el autor, era consistente con la visión limitada del concepto de subsidiariedad guzmaniana al que ya nos referimos. Esto implicaba dos cosas. Por un lado, una desconfianza natural respecto del Estado y su tamaño, sin interrogarse demasiado sobre la existencia de fallas de mercado (y la consecuente necesidad de regulación), problemas de competencia o los ámbitos donde el alcance del mercado 
podía tener limitaciones. Por otro, una suerte de desprecio por lo colectivo y ausencia de preocupación respecto a los cuerpos intermedios de la sociedad civil. Mansuy ve, acertadamente a mi juicio, que esta sobre simplificación de las indudables bondades del mercado termina afectando su legitimidad, ya que lo desconecta de la esfera pública y permite incubar la desconfianza de la que hoy es presa.

Si se trataba de defender los fundamentos del modelo, no bastaba con anclarse en cifras de crecimiento, nos dice Mansuy. Pese a ser innegable que Chile había progresado como nunca en su historia, la derecha cayó en el error de considerar que eso era políticamente suficiente. De la misma forma, el empresariado, tradicionalmente asociado a la derecha, se contentaba con apelar a su rol en el crecimiento económico y la generación de empleo. Indudablemente, ambas dimensiones son fundamentales - ¿cómo redistribuir y hacer política social sin crecimiento?; ¿cómo avanzar en derrotar la pobreza sin empleo?-, pero están lejos de ser suficientes. Por esta misma razón, nos dice el autor, la derecha tradicionalmente minimizó el problema de la desigualdad (y algunos lo siguen haciendo), sin ofrecer una teoría de justicia respecto a cuáles desigualdades son inaceptables y cuáles, bienvenidas.

La derecha, así vista, se preocupó de la economía a secas, dejando a un lado su dimensión realmente relevante: la economía política. Por ponerlo de alguna manera, y ésta es una lectura personal del asunto, se quedó con los titulares de la mano invisible de Adam Smith: el laissezfaire y el egoísmo del carnicero, pero sin darse el trabajo de escrutar más allá en la complejidad de su obra, ya sea en la Riqueza de las naciones o en la Teoría de los sentimientos morales. Siendo la búsqueda de ganancias un elemento esencial, para Smith está lejos de ser lo único importante. Conceptos como sociedad, Estado, confianza, justicia, solidaridad, benevolencia, reciprocidad y simpatía son fundamentales en el pensamiento del escocés. ${ }^{7}$ Contrariamente a lo que suele achacársele, Smith no tiene una oposición dogmática contra la regulación estatal, la que considera necesaria para el buen funcionamiento del mercado. Tampoco condena el rol del Estado en asuntos sociales. Le preocuparon la pobreza y la desigualdad, promoviendo acciones redistributivas tales como impuestos progresivos (moderados) y la provisión de educación

${ }^{7}$ Para un excelente ensayo sobre este punto, ver Amartya Sen, "Capitalism Beyond the Crisis", The New York Review of Books, marzo 26, 2009. 
pública. Fue también un crítico de las asimetrías entre patrones y trabajadores que podían limitar sus salarios.

Hay buenas razones para creer que la visión limitada de la subsidiariedad tuvo un correlato fundamental en una versión también empobrecida del liberalismo que supuestamente la derecha impulsó. Un "liberalismo estrecho", como lo llama Mansuy. Porque el liberalismo no puede reducirse a su dimensión económica y, al mismo tiempo, sospechar de la libertad individual en la realización de proyectos de vida diversos, esto último algo muy patente en la derecha conservadora. El liberalismo es esencialmente un concepto político cuyo norte último es el buen vivir, no en forma aislada, sino en sociedad. Como bien lo planteara David Hume, uno de los pensadores fundamentales del liberalismo clásico, ${ }^{8}$ no significa el utilitarismo individualista y calculador a la Bentham ni el egoísmo a secas y a todo evento.

Ocurre, y éste es un punto en el que Mansuy no repara, que en el discurso de derecha se observa una confusión conceptual respecto del liberalismo. Y es que allí donde se apela al liberalismo pareciera que en realidad se refiere al libertarismo, conceptualización bajo la cual la libertad económica es el principio supremo e inviolable, con preeminencia sobre cualquier consideración. Por eso mismo, tampoco es de extrañar que, al hablar de libertad, sin duda un valor fundamental del ideario de derecha, se la haya pensado estrictamente en su dimensión negativa, sin cuestionarse por las perjudiciales implicancias de tal reduccionismo. ${ }^{9}$ Mansuy es enfático: "La derecha se quedó en silencio, porque la

${ }^{8}$ En sus Investigaciones sobre los principios de la moral, Hume señala: "Parece, asimismo, que, en nuestra general aprobación de caracteres y modos de conducta, la tendencia útil que poseen las virtudes sociales no nos mueve por ninguna consideración de interés egoísta, sino que tiene una influencia mucho más universal y amplia. Parece que una tendencia al bien público y a promover la paz y la armonía y el orden de la sociedad, siempre nos pone del lado de las virtudes sociales, al afectar los principios benevolentes de nuestra especie" (Madrid: Alianza Editorial, 1993), 104.

${ }^{9}$ Como lúcidamente nota Vargas Llosa: "El gulag de los paraísos socialistas es el resultado de una libertad meramente 'social' [positiva], que desprecia la libertad 'negativa', aquella que defiende al individuo contra la autoridad. Y las monstruosas desigualdades sociales y económicas y las iniquidades de la explotación de ciertas sociedades, la consecuencia de cifrar todo el progreso en la libertad 'negativa', desdeñando por entero la "positiva"” ("Sabio, discreto y liberal", diario El País, 16 de noviembre, 1997). 
adhesión irrestricta al mercado y a la libertad negativa permite decir poco, muy poco, sobre los fenómenos propiamente políticos" (141).

Es crucial subrayar - y Mansuy no lo hace - que el liberalismo, al menos el clásico, no trata la libertad económica como un bien absoluto que tenga preeminencia sobre otros derechos y libertades fundamentales..$^{10}$ Desde esta perspectiva, la libertad económica es compatible con una visión sofisticada de la subsidiariedad como la que Mansuy reivindica, con un rol del Estado que financie la provisión de bienes públicos, que impulsa políticas sociales para corregir desigualdades y garantizar oportunidades, que proporciona redes de protección y fomenta una sociedad civil vigorosa. En mi opinión, esta confusión conceptual ha sido en extremo dañina y ha convertido al liberalismo a la chilena en un blanco fácil de críticas desde la izquierda (desde ya apelando a ese comodín llamado "neoliberalismo", que parece servir para dar cuenta de todos los males).

Pero incluso supeditado al ámbito económico, el reduccionismo del término subsiste. Se ha transformado en un lugar común aducir que la concentración económica, la falta de competencia, los abusos empresariales, el uso de información privilegiada, la captura regulatoria, el capitalismo de amigos y una serie de otras malas prácticas que han venido minando la legitimidad del mercado son lo propio del liberalismo económico en tanto doctrina. Pero cualquiera que haya leído a Adam Smith sabe que el liberalismo económico rechaza con firmeza esas prácticas y plantea drásticas sanciones, precisamente porque minan la legitimidad y afectan el adecuado funcionamiento del mercado. Lo suyo, a fin de cuentas, es luchar contra la concentración del poder, los privilegios, $\mathrm{y}$, sobre todo, bogar en favor de la competencia, un clamor que en su versión contemporánea ha planteado con claridad una serie de autores. ${ }^{11}$

Las precisiones anteriores son relevantes ya que implican que la crítica que suele hacérseles a los "excesos del liberalismo económico",

${ }^{10}$ Una excelente discusión sobre este punto se encuentra en John Tomasi, Free Market Fairness (Princeton: Princeton University Press, 2012). Ver además la lúcida reseña de este libro efectuada por Pablo Ortúzar en Estudios Públicos 142 (2016).

${ }^{11}$ Ver, por ejemplo, Rajan y Zingales, Saving Capitalism; Zingales, A Capitalism for; Daron Acemoglu y James Robinson, Why Nations Fail. The Origins of Power, Prosperity, and Poverty (New York: Crown Business, 2012); Niall Ferguson, The Great Degeneration (London: Allen Lane, 2013). 
incluyendo las del propio Mansuy, debiera ser más bien una crítica a una visión distorsionada de lo que realmente significa. Una que peca por defecto y no por exceso. Nuestro autor no parece reparar en este punto, ya que su preocupación última apunta a otro lado. Ve en la autonomía del sistema económico y en la expansión del mercado una "colonización" y una enajenación progresiva de la vida social. De acuerdo a Mansuy, ésa sería la razón por la que "la gente percibe a las empresas como adversarios que quieren perjudicarlos" (97). En otras palabras, la expansión del mercado estaría en el origen de su desconfianza. Pero este punto es muy discutible. Como bien advertía Smith, lo propio de la sociedad comercial (de mercado) son sus altos niveles de confianza. Sin ésta, la infinidad de intercambios impersonales que la caracterizan sería imposible (en un trabajo reciente, Dan Ariely y coautores ofrecen una validación empírica interesante de esta idea). ${ }^{12}$ En su crítica, lo que nuestro autor parece tener en mente es a grandes corporaciones que todo lo abarcan y que ven a sus consumidores como enemigos, lo que está lejos de ser obvio. Pero incluso si éste fuera el caso, ignora que el mercado está constituido además por miles de pequeños y medianos emprendimientos que hacen amable nuestra vida cotidiana y que, en consecuencia, distan de ser percibidas con la desconfianza que señala.

Los malentendidos sobre el liberalismo económico y las malas prácticas son particularmente patentes respecto al concepto de competencia. Mansuy critica, con razón, los contratos con "letra chica", la existencia de cláusulas difíciles de descifrar por el consumidor o planes de servicios (de isapres, por ejemplo) incomparables. Sin embargo, parece errar el punto al atribuir estos problemas a un exceso de competencia, por ejemplo, cuando señala que "cuando se despliegan las lógicas menos amables de la competencia capitalista, los escándalos financieros o empresariales se vuelven más bien normales" (98). Lo cierto es que los abusos que subraya no son por un exceso de competencia, sino por todo lo contrario (volveremos sobre este punto en la sección siguiente). Sólo cuando hay falta de competencia una empresa puede darse el lujo de abusar en los términos planteados sin recibir sanción de mercado alguna. De allí que la preocupación por una intensa competencia efectiva

12 Dan Ariely, Ximena García-Rada, Lars Hornuff y Heather Mann, "The (True) Legacy of Two Really Existing Economic Systems", Munich Discussion Paper 2014-26, Department of Economics, University of Munich. 
sea una de las reivindicaciones fundamentales del liberalismo económico bien entendido.

La confusión anterior es importante, ya que proporciona una clave relevante de las dificultades que enfrenta el ideario de derecha. Durante largos años buena parte de este sector ha confundido la defensa del empresariado con la defensa del mercado, que es lo propio del liberalismo. Una derecha que se presenta como paladín del liberalismo debiera haberse erigido también en el paladín de la libre competencia, liderando leyes y sanciones exigentes para atentados contra ésta; debería haber mirado con sospecha la concentración de los mercados o las rentabilidades sobre normales; debería haber denunciado con fuerza los abusos contra consumidores y las malas prácticas empresariales en general. Pero poco de eso ocurrió. Nuestra derecha carga con la pesada mochila de haber sido más pro empresa que pro mercado, un rumbo a enmendar en cualquier proyecto político de largo plazo que desee llevar adelante.

\section{LA IZQUIERDA Y EL RÉGIMEN DE LO PÚBLICO}

Karl Popper, refiriéndose a Marx, señalaba que uno debía valorar y apreciar las fortalezas (intelectuales y argumentativas) de su oponente si quería combatirlo con éxito en el plano intelectual. ${ }^{13}$ Daniel Mansuy hace honor a esta máxima en el capítulo que le dedica a la tesis del régimen de lo público, de Fernando Atria, en el cual desarrolla una crítica fina y lúcida de las contradicciones y defectos que subyacerían en ella. Mansuy hace el ejercicio honesto de buscar entender los argumentos de su adversario, reconociendo que tuvo "el mérito - nos guste o no- de haber sido uno de los pocos que comprendieron la naturaleza del momento" (106). Y al hacerlo destaca "que su propuesta es sin duda una de las elaboraciones más acabadas de aquello que podríamos llamar la post-transición" (107). La importancia del trabajo de Atria es indudablemente política. A fin de cuentas, fue el marco conceptual detrás del cual se articuló el movimiento estudiantil y la tesis en torno a la cual ha girado el programa de la Nueva Mayoría.

${ }^{13}$ Karl Popper, The Open Society and Its Enemies (Princeton: Princeton University Press, 2013), prefacio a la $2^{\mathrm{a}}$ edición. 
Mansuy presenta el régimen de lo público como un cambio de paradigma que "busca, principalmente, sacarnos de las relaciones colectivas fundadas en el egoísmo propio del neoliberalismo, para permitirnos acceder a un ideal de realización recíproca, donde pueda emerger un interés genuino por el otro" (110). Y este paradigma está estrechamente ligado a los llamados derechos sociales, los cuales sólo podrían existir, según Atria, en ausencia de mercado. Es decir, en un contexto en que el ejercicio de ese derecho social (educación, por ejemplo) está desconectado de la capacidad de pago de los individuos. Aunque los derechos sociales son consustanciales al régimen de lo público, no son lo único. Mansuy nos recuerda que Atria plantea la extensión de lo público a otras dimensiones, tales como tener un canal de televisión o un banco estatales (por supuesto, la lista podría ser larga).

La crítica de Mansuy a la tesis de Atria se divide en dos partes. La primera es metodológica y se refiere a la idea de paradigma (de lo público). La segunda, a las falencias que tendría la tesis misma.

Respecto al primer punto, nuestro autor cuestiona la idea según la cual el paradigma de lo público sería una suerte de resultado evolutivo inevitable llamado a reemplazar al paradigma "neoliberal" que lo antecede y que empieza a ser cuestionado en 2011. Para entender el punto, es útil recordar lo que sería la progresión lógica hacia el momento histórico de los derechos sociales según Atria: si los derechos civiles fueron sucedidos por los derechos políticos, éstos serían sucedidos por los derechos sociales. Para Mansuy, esta progresión es discutible en tanto implica suponer, a priori, una cierta dirección de la historia en la cual el nuevo paradigma social es siempre superior y reemplaza al anterior. En este sentido, su crítica es similar a la que hace Popper a las teorías historicistas, cuya pretensión determinista está amparada en meras profecías históricas, algo así como la revelación divina de un iluminado que sepa algo que el resto no. Mansuy reclama con acierto que, si bien la superioridad de un nuevo paradigma puede tener sentido en las ciencias naturales, esto está lejos de ser cierto en las ciencias sociales. Más aún, en presencia de paradigmas inconmensurables que compiten entre sí, se hace imposible establecer, sin más, la superioridad de uno sobre el otro. Por eso reclama con fuerza que "a Atria le parece evidente la superioridad de lo público sobre el neoliberalismo, pero eso no constituye un argumento desde su óptica ni desde ninguna (y él lo sabe)" (111). 
A las críticas anteriores, cabría agregar una que Mansuy no aborda: la progresión "lógica" derechos civiles-políticos-sociales falla - o cuando menos está lejos de ser evidente-, si consideramos que mientras las dos primeras fuentes de derechos son eminentemente políticas, la tercera es, además, económica, es decir, contingente a los recursos disponibles para asegurar dichos derechos. Y si esos derechos se definen, como Atria lo hace, desligados de la capacidad de pago de las personas, se sigue que deben ser asegurados por el Estado de forma universal, uniforme (a todos los mismos e impidiendo que se pueda obtener más en el mercado) y sin mediar pago alguno. El igualitarismo resultante implica que el nivel efectivo del derecho garantizado se nivela "hacia abajo" y que dicha nivelación será tanto mayor cuanto mayor sea el set de derechos sociales que se definan. Este resultado tiene consecuencias sociales y de economía política que hacen que diste de ser obvio que la sucesión lógica que se reclama sea realista. Importa, además, renunciar a la focalización hacia los que corren con más desventaja, principio de justicia distributiva que a Atria no inquieta, por cuanto, erróneamente, concibe que la focalización necesariamente significa asegurar un derecho de baja calidad para pobres. ${ }^{14}$

Hechas las objeciones metodológicas, Mansuy ataca los elementos de fondo del paradigma de lo público. Recordemos que éste plantea un reemplazo del paradigma "neoliberal" por uno de relaciones colectivas, en el que aflore el interés general en lugar de los intereses particulares intermediados por el mercado, al menos en algunos ámbitos de la vida (los de los derechos sociales, por de pronto). Se trataría, recuerda nuestro autor citando a Atria, de moverse desde "formas más inhumanas a formas más humanas de vida en común” (115). ¿Dónde residiría lo inhumano del paradigma neoliberal según Atria?, se pregunta Mansuy. Su interpretación es la siguiente: el mercado encarnaría "algún tipo de inhumanidad, en cuanto nos conduce a consideraciones puramente individuales, sin que nunca antes quede integrado en nuestro horizonte el bienestar del otro" (116).

${ }^{14}$ Como es obvio, para una cantidad de recursos dada, la focalización en los más desaventajados les asegura a estos un acceso a una calidad más elevada que cuando esos mismos recursos deben repartirse universalmente entre desaventajados y aventajados. 
Para hacer más atractiva esta dicotomía, Atria, nos dice Mansuy, apela a casos extremos. Por ejemplo, si una gran empresa paga a sus proveedores a 150 días, esto sería lo propio del mercado. Pagar en menos tiempo sin estar obligado o invertir en relaciones de confianza sería no entender la esencia misma del mercado, cual es la maximización del beneficio propio. Por eso, bajo la lógica del mercado apenas se buscaría cumplir con el mínimo legal. Si ella lo permitiese, los empleadores tendrían a sus trabajadores en condiciones de miseria, llenarían de letra chica a sus consumidores y mantendrían pobres relaciones con las comunidades en las que se insertan, etcétera. Para Mansuy obviamente esta lectura es excesiva, al borde de la caricatura. Simplemente apunta a hacer más seductor el paradigma de lo público llamado a reemplazar tamaña inhumanidad. Y es que, argumenta acertadamente Mansuy, si bien la búsqueda de ganancia es consustancial al mercado, ello está lejos de decir que cualquier otra consideración deba ser desechada.

A la crítica anterior cabe agregar una objeción sustantiva que Mansuy omite y a la cual ya nos referimos en la sección anterior: los excesos a los que Atria apela sólo son compatibles con mercados en que la competencia no opera. Sólo allí una parte puede darse el lujo de abusar de la otra en los términos planteados. En mercados competitivos, una actitud de ese estilo redundaría en una menor ganancia, lo que implica que su búsqueda conduciría al resultado contrario al que Atria supone. Por cierto, tener mercados perfectamente competitivos es una abstracción, tal cual lo señalaba Hayek. Pero el punto de fondo es que en los mercados reales hay niveles elevados de competencia en múltiples áreas. En consecuencia, resulta cuestionable asimilarlos con su peor versión, que es cuando no hay competencia alguna. Y, por último, si se va a comparar la visión idealizada de lo público, lo ecuánime sería hacerlo también con la visión también idealizada de la competencia perfecta. Lo contrario es hacer trampa.

Despejado el punto, Mansuy trata dos objeciones centrales de la tesis de lo público. Primero, su plausibilidad y aplicabilidad real, y, segundo, su conflicto con la libertad. Respecto de lo primero, el autor critica que se presenten todas las miserias humanas que serían propias de la lógica neoliberal, pero se omita siquiera indagar en los costos y miserias propias de la implementación del régimen de lo público en el mundo real. Amén de consideraciones de bienestar, ocurre que lo público debe 
intermediarse a través de funcionarios estatales de carne y hueso. Así, hay una serie de pertinentes preguntas que Mansuy plantea: “¿Por qué habríamos de confiarle a un puñado de personas tamaña responsabilidad? Si estamos de acuerdo en que la concentración del poder es peligrosa en el mercado, ¿por qué aceptarla sin más cuando viene del Estado? ¿Por qué esas personas, por el solo hecho de trabajar en una repartición pública, estarían exentas de perseguir fines particulares?" (123).

Con todo, la objeción mayor proviene de los excesos en que puede caer el régimen de lo público y de los derechos sociales, incluyendo limitaciones groseras de la libertad de los individuos y de la sociedad civil. Ocurre, nos dice Mansuy, que, en su versión última, la crítica contenida en el régimen de lo público va más allá de la mera expresión del mercado plasmada en el pago o en el lucro. Lo que ataca es toda búsqueda o defensa de intereses particulares en las relaciones humanas. Visto así, Mansuy plantea certeramente que el régimen de lo público cuestionaría también las diversas expresiones de la sociedad civil que, sin ser motivadas por el afán de lucro, estarán siempre caracterizadas por la búsqueda de intereses particulares o grupales. Surge así una suerte de monopolio de un régimen de lo público, aséptico, desprendido de cualquier interés particular, y, al hacerlo, se comprometen libertades básicas que constituyen una parte estructurante y esencial de la vida en sociedad.

Es del caso notar la sorprendente similitud del paradigma de lo público con el de la voluntad general de Rousseau ${ }^{15}$ (y resulta curioso que Mansuy no repare con fuerza en ella). Y es que la voluntad general también supone ciudadanos desprendidos de todos sus intereses particulares, agregando estas voluntades puras en un soberano, el pueblo, que será así la expresión prístina, siempre recta, del interés general. Para Rousseau el hombre debe quedar sometido a la voluntad general y es bajo ese sometimiento que radicaría su verdadera libertad. Las similitudes con la voluntad general hacen que el régimen de lo público, en su versión extrema, sea sujeto a las mismas críticas de las que ha sido objeto la primera: ${ }^{16}$ su constructivismo desanclado de la realidad; un

${ }^{15}$ Nótese que, tratándose de un paradigma que ya tiene 250 años, esto de paso contradiría la idea ya discutida de Atria respecto a que los paradigmas van siempre hacia adelante.

${ }^{16}$ Ver, por ejemplo, Isaiah Berlin, Freedom and its Betrayal: Six Enemies of Human Liberty (Princeton: Princeton University Press, 2002). 
desprecio por la libertad negativa en favor de una libertad meramente social; un igualitarismo castrante que atenta contra el pluralismo, y, por último, el riesgo de caer en la tiranía de las mayorías y el totalitarismo.

Una manera de ilustrar algunos de los problemas anteriores es tomando la discusión educacional, tema prioritario para Atria y que Mansuy repasa con atención. En tanto derecho social, el régimen de lo público plantea que cualquier lógica de mercado debe ser aquí erradicada. Y esta lógica, ya está dicho, admite dos expresiones. Su forma más inmediata es la de eliminar toda forma de pago en la materia, lo que implicaría abolir no sólo los colegios particulares pagados, sino que cualquier pago que realicen los padres. No habiendo pagos privados, una consecuencia lógica es que esta uniformización implica una nivelación hacia abajo en su provisión, lo que tiende a un igualitarismo de facto en la calidad: nadie podría así tener una educación distinta o superior de lo que el régimen de lo público establezca. Mansuy subraya con justeza que esto entra en conflicto con la libertad de enseñanza. Y a su objeción cabría agregar otra no menos importante: negar la posibilidad de que una persona pueda aspirar a una educación de mayor calidad implicaría, tal como lo señala Elizabeth Anderson, tratarla como un ciudadano de segunda clase $^{17}$ y atentar contra un bien humano intrínseco, cual es el desarrollo de los talentos. ${ }^{18}$

Si la abolición de cualquier pago en educación es una primera fuente de conflicto, cabe agregar una segunda, bien advertida por Mansuy. Dado que el paradigma de lo público reniega de cualquier interés particular, entonces también resultarían problemáticos los proyectos educativos con ideario. Nuestro autor toma el caso de la educación superior (y lo ilustra con la Universidad Católica), destacando que tal premisa implicaría un atentado al pluralismo y a la diversidad de proyectos

17 Elizabeth Anderson, "Rethinking equality of opportunity: Comment on Adam Swift's How Not to be a Hypocrite", Theory and Research in Education 2, n. ${ }^{\circ} 2$ (2004): 106.

${ }^{18}$ Elizabeth Anderson, "Fair Opportunity in Education: A Democratic Equality Perspective", Ethics 117, n. 4 (2007): 615. A estas objeciones podría replicarse que aspirar a más supone pagar más. Siendo esto en principio cierto (no necesariamente), la pregunta es bajo qué argumentos debiera impedirse a una familia sobre invertir en su hijo. Considérese además que esa sobre inversión puede lograrse privándose de gastar en otras cosas (por ejemplo, salir de vacaciones). ¿Es razonable prohibir ese esfuerzo? 
educativos; un argumento que, por supuesto, también vale a nivel de colegios y lleva a la misma conclusión: la ficción de desprenderse de todo interés particular en estos ámbitos conduce necesariamente a aniquilar cualquier expresión vigorosa de la sociedad civil y del pluralismo que de allí emerge.

Mansuy va todavía un paso más allá y se pregunta: ¿Si cualquier expresión de intereses particulares es censurable, la influencia de la familia, esto es de sus intereses en la educación de sus propios hijos, también debiera ser abolida? A este respecto nos recuerda que el propio Atria se muestra contrario a la idea de utilizar la excelencia académica como criterio de primer orden en selección de estudiantes universitarios. Ello, porque dicha medida estaría estrechamente correlacionada con el nivel educativo de los padres, no garantizando, entonces, que la educación sea entendida como un derecho. El punto es extremadamente problemático por dos razones. Por un lado, como señala Mansuy, porque choca directamente con la familia, ya que, así vista, sería una censurable fuente de transmisión de privilegios. ¿Censurable? Lo concreto, nos recuerda nuestro autor, es que "buena parte de lo que somos es, de algún modo, el resultado de lo que nuestros padres o nuestro entorno hicieron o dejaron de hacer" (127). Impugnar ese quehacer sería renunciar a la responsabilidad de los padres. "iQué queda de la sociedad si asumimos tal perspectiva?" (128), se pregunta Mansuy. El segundo problema mayor, que a mi juicio nuestro autor no destaca lo suficiente, es el siguiente: suponer que un resultado está dado determinísticamente por la transmisión de privilegios de los padres implica negar por completo el reconocimiento del mérito. Y cuando esto ocurre nos enfrentamos tanto a un problema de justicia como a uno de incentivos. La tesis de Atria choca aquí con el insalvable problema epistemológico del igualitarismo de la suerte en la que se ampara: ante la dificultad de poder identificar exactamente el componente de mérito detrás de toda acción, se asume por defecto que, en realidad, no hay ninguno.

\section{EL DESAFÍO DE ENCAUZAR LA MODERNIDAD}

En el capítulo final, Daniel Mansuy intenta una mirada de futuro y ofrecer algunas claves para superar el impasse en que la política se encuentra sumida, ello en el entendido - consistente con lo que el au- 
tor ha planteado durante todo el libro- de que la condición necesaria para salir del embrollo es a través de más política. Este ejercicio, nos señala, debiera apuntar a generar un diagnóstico compartido, un nuevo consenso, sobre las razones últimas detrás del malestar y las acciones necesarias para encauzarlo. Ello supone, continúa el autor, reconocer la necesidad de "aproximarnos a la realidad reconociendo su carácter multiforme" y "escapar de los reduccionismos que se disputan la hegemonía de la discusión pública" (la del régimen de lo público y la del "liberalismo económico") (153).

Aunque el capítulo ofrece pistas interesantes puede decepcionar las expectativas del lector. Y es que, luego de un análisis acabado del germen institucional en que se sustentarían las falencias políticas actuales, de las carencias del proyecto político de la derecha y de las contradicciones y riesgos del régimen de lo público que subyace al proyecto de la izquierda, el lector queda en posición expectante sobre la cartografía que Mansuy fuera a dibujar en la recta final de su libro, particularmente respecto al ideario político de la centroderecha. En cambio, Mansuy opta deliberadamente aquí por una cartografía muy genérica, lejos de plantear una hoja de ruta política más detallada.

Mansuy ancla el problema político que tenemos a la vista en la modernidad a la que Chile accedió; una que objetivamente ha ampliado, como nunca en nuestra historia, las libertades y condiciones sociales, educativas y de consumo de los chilenos, y que, en consecuencia, también plantea nuevas exigencias, desafecciones por resolver y expectativas por satisfacer. Si fijar el problema en este ámbito parece pertinente, entonces retoma su importancia la pregunta que hiciéramos en secciones anteriores sobre si la crisis política de Chile es idiosincrática a su institucionalidad política o, bien, no ofrece realmente una excepcionalidad respecto a las tensiones propias de la modernidad en cualquier latitud.

Si lo propio de la modernidad es la expansión del mercado (y la especialización resultante), los mayores espacios efectivos para la construcción de proyectos de vida individuales y la diversidad que ello supone, Mansuy plantea que esto tiende a erosionar el sentido de comunidad de lo público. Esta es la tensión fundamental que el sistema político tendría que resolver. Por supuesto, nos recuerda acertadamente Mansuy, lo público no puede ser sinónimo de lo estatal o de "aquello 
que podamos crear desde el diseño centralizado" (172). Ello engendraría el riesgo de uniformar y diluir la diversidad desde la cual debe, precisamente, construirse lo público. Y es que de lo que se trata, nos dice el autor, es de apelar a "una unidad en la diversidad" (170). A su vez, si la diversidad es la marca de la modernidad, Mansuy es consciente de que el mercado, "bien entendido", juega un rol esencial en tanto "soporte indispensable de esa pluralidad" (172).

Así las cosas, ¿cómo entender que mercado y diversidad, que constituyen la esencia de la modernidad, sean, al mismo tiempo, los ingredientes esenciales para paliar la "erosión" comunitaria que generan? La respuesta de Mansuy pasa necesariamente por una limitación del mercado y de los grados de diversidad.

Respecto al mercado, nuestro autor se pregunta: “¿Hasta dónde queremos que llegue? ¿Debe la lógica económica gobernar todos los aspectos de la vida social?" (161). Apelando al caso general (esto es, dejando a un lado las situaciones ilegales o francamente reñidas con la ética), el criterio al que apunta para responder a estas interrogantes sería más o menos el siguiente: hasta el punto en que no erosione vínculos sociales relevantes. De aquí, por ejemplo, que Mansuy cuestione la forma como un mall o un supermercado, que, bajo su mirada, destruyen el sentido de pertenencia comunitaria asociado con la pérdida del comercio de barrio. Siendo atendible el punto, el problema es cómo y quién determina el criterio. ¿Debiéramos prohibir la liberalización del comercio amparados en que afectaría la identidad de la agricultura nacional? ¿Subsidiar a las minas de carbón bajo el mismo argumento? ¿Proteger el cabotaje marítimo local so pretexto de no afectar la tradición de nuestra marina mercante?

El punto que levanta Mansuy es complicado, además, porque la relevancia de los vínculos sociales es difícil de precisar. ¿Qué pasa si la expansión del mercado erosiona ciertos vínculos relevantes pero, al mismo tiempo, fortalece otros? Por ejemplo, una gran industria textil podría destruir al pequeño productor local, pero, en paralelo, fortalecer el sentido de pertenencia de sus empleados. Y ¿qué pasa si la expansión del mercado se da en dimensiones que robustecen el sentido de comunidad? Mansuy minimiza esa posibilidad, ya que la noción de mercado que parece tener en mente presupone que se construye en un indivi- 
dualismo eminentemente desconectado del otro, lo que, por cierto, es una simplificación. Desde ya, porque en su dimensión política el individualismo - que significa la protección de los derechos y libertades individuales - no implica negar lo colectivo. Si lo propio del mercado fuera estar siempre desconectado del otro, ¿cómo explicar la expansión del mercado de la cultura o del arte? ¿El avance de empresas B, de las cooperativas o de una serie de emprendimientos sociales? Lo concreto es que, entendido en un sentido amplio, el mercado también supone el intercambio de una larga lista de cosas social y comunitariamente valiosas gracias a un individualismo que, en el quehacer cotidiano, es mucho más que interés egoísta.

Vayamos ahora a la relación entre diversidad y modernidad. Mansuy es consciente de la importancia de la primera para la vida en sociedad, pero también expresa su preocupación por su efecto en el sentido comunitario o de unidad. Esta tensión parece difícil de resolver. Y lo es, porque, al final del día, la diversidad no es sino la expresión de los mayores grados de libertad que surgen de la modernidad. ¿Libertad para qué? Esencialmente para construir autónomamente los legítimos y diversos proyectos de vida. Y es también a partir de esa individualidad, de eso que Tocqueville llamó "voluntades individuales"19, que debiera fundarse cualquier expresión asociativa que provea sentido de pertenencia. Aunque Mansuy no se pronuncia explícitamente sobre este punto, deja entrever que esa diversidad individual debiera limitarse. Por eso es que se muestra crítico de la emancipación individual a nivel de "la sexualidad, de la familia, de la sociedad, de la nación, de los códigos morales, de las tradiciones y costumbres" (150).

Mansuy plantea certeramente que un vehículo fundamental para aplacar las tensiones que surgen de la modernidad es el potenciamiento de la sociedad civil y de las comunidades. Una sociedad civil vigorosa es, nos dice, por un lado, un canal para generar sentido de pertenencia y expandir los lazos comunitarios $\mathrm{y}$, por otro lado, una forma para que lo

${ }^{19}$ En su relato y reflexiones sobre el vigor de la sociedad civil que observa en Estados Unidos, Tocqueville señala: "Independientemente de las asociaciones permanentes creadas por la ley bajo el nombre de comunas, ciudades y condados, hay una multiplicidad de otras más que no deben su existencia y su desarrollo sino a las voluntades individuales". Alexis de Tocqueville, De la Démocratie en Amérique (París: GF-Flammarion, 1981), Deuxième Partie, cap. IV, 274. 
público no sea monopolio de lo estatal. Parte de nuestro acuerdo político, en consecuencia, pasaría por incentivar la emergencia de esos cuerpos intermedios que maravillaron a Tocqueville en su visita a Estados Unidos y que cobran hoy plena vigencia política; expresiones y asociaciones de la sociedad civil que - es bueno volver a insistir — basan su existencia y vigor en las "voluntades individuales" y no en una suerte de colectivo abstracto y preexistente al que éstas se deban. Siguiendo a Tocqueville, Mansuy plantea que el fortalecimiento de la sociedad civil requiere acercar las decisiones políticas a las comunidades, de forma tal de romper la distancia entre el bien individual y el bien público. No se trata de caer en la ilusión de la democracia directa, advierte con mucha razón nuestro autor, sino de tomarse en serio la descentralización. Mansuy también aboga por reivindicar el espacio público como lugar de encuentro y generación de lazos comunitarios, incluyendo plazas y parques, hoy tan desigualmente distribuidos, temas, sin duda, en los que Chile está muy al debe. Con justeza plantea, finalmente, que la familia es la unidad asociativa por esencia y que ésta requiere ser apoyada (suponemos que en sus diversas expresiones). Más discutible, en cambio, resultan sus propuestas sobre las herramientas para hacerlo, por ejemplo, incentivando la natalidad a través de franquicias tributarias.

Al finalizar, quiero señalar que se echa de menos en este capítulo final una referencia al problema de la desigualdad, sin duda uno de los temas de fondo que está y seguirá estando en el debate político chileno. Esta omisión es más sorprendente aún si consideramos que en capítulos anteriores Mansuy señalaba acertadamente que, en especial desde la derecha, se necesitaba una reflexión profunda anclada en una teoría de justicia que permitiera distinguir qué tipo de desigualdades son bienvenidas y cuáles inaceptables. Y es que, al final del día, la modernidad y buena parte de sus tensiones y desafíos parecen tener que ver precisamente con esto: por un lado, con valorar la desigualdad que emana del mérito y de la construcción libre de proyectos de vida diversos; por el otro, con buscar aplacar las desigualdades injustas, ésas que surgen cuando el acceso a capacidades habilitantes para en el desarrollo de los proyectos vitales y el acceso a recompensas o reconocimientos basados en el mérito no están disponibles para todos. $\mathrm{Y}$ en esa necesaria reflexión, no cabe duda de que la lucidez y profundidad que Daniel Mansuy despliega en este libro serían de inmenso valor. $E P$ 